\title{
CLINICAL AND RADIOGRAPHIC EVALUATION OF COLLAGENATED CORTICO-CANCELLOUS BONE GRAFT AFTER MANDIBULAR CYST ENUCLEATION
}

\author{
Abdelrahman S. El-ghamrawy' $B D S$, Nevine S. Mohammed ${ }^{2} P h D$, Lydia N. Melek ${ }^{3} P h D$
}

\begin{abstract}
INTRODUCTION: Dental cysts constitute a considerable share in the jaw bones disorders. The cystic lesions are the major factor causing jaw destruction. Bone grafts are used to reduce risk of jaw weakness and to shorten the period of healing after cyst enucleation.

OBJECTIVES: To evaluate the influence of collagenated heterologous cortico-cancellous bone mix radiologically and clinically after enculeation of mandibular cysts.

MATERIALS AND METHODS: A total of twenty-four patients suffering from cysts affecting the lower jaw bones and seeking for surgical treatment. Patients were assigned into 2 parallel groups with allocation ratio 1:1.

Group A: Consisted of twelve patients, into whom Collagenated heterologous cortico-cancellous bone mix (Osteobiolß Gel 40 E, Italy) was applied as grafting material after enculeation of mandibular cyst.

Group B: consisted of twelve patients with enculeated cyst without applying any grafting material acting as control.

A cone beam computed tomography was performed for each patient to evaluate bone density immediately and after 6 months.

RESULTS: Radiographic analysis using cone beam computerized tomography revealed that there was gradual increase in bone densities in the grafted defects. The mean value of bone density pre-operatively was $734.8 \pm 105.1 \mathrm{HU}$ which increased to $1634.4 \pm 222.2 \mathrm{HU}$ at the end of the follow up period.
\end{abstract}

CONCLUSIONS: The use of collagenated cortico-cancellous bone graft greatly enhances bone deposition in bony defects.

KEYWORDS: mandibular cysts, collagenated heterologous cortico-cancellous bone mix and surgical bone defect.

1- Dentist at El-Raaya Hospital Ministry of Health, Alexandria, Egypt.

2- Professor of Oral and Maxillofacial Surgery, Faculty of Dentistry, Alexandria University, Egypt

3- Lecturer of Oral and Maxillofacial Surgery, Faculty of Dentistry, Alexandria University, Egypt.

\section{INTRODUCTION}

Bone volume preservation is very important to obtain good esthetic result (1), thus in order to obtain this goal it dictates a surgical technique that is just as effective as other techniques in the removal of the disease but more optimal for facilitating future reconstructive efforts (2).

One of the most common causes of bone defects is the cyst. Cyst is in fact a pathological cavity typically with the epithelial cellular lining, getting fluid inside, semifluid or perhaps gaseous materials and not due to accumulation of pus. While, some other types of cysts such as mucous extravasation cysts, aneurysmal traumatic bone cysts are not lined by epithelium (3).

Additionally, some other different cysts occurring in skeleton are known as pseudo cyst (4).

The treatment of jaw cyst of the oral cavity is predominantly surgical and there are two basic types of operative procedures: Total enucleation and marsupialization (5).

Enucleation means complete removal or separation of cyst lining from inner side of bone cavity and allows physiological healing of cavity by blood clot. It is indicated in cysts which are readily accessible, cysts which do not extensively involve vital teeth or soft tissues or encroach on nearby vital structures $(5,6)$.

Marsupialization of cyst involves the creation of a pouch which can be produced surgically through creating a window by removing a section of the overlying mucoperiosteum, and adjacent cyst wall to decrease intracystic tension. The border of the incised mucosa is then sutured to the border of the cyst wall that has been cut $(7,8)$. Marsupialization is indicated in the very elderly individuals or for patients who are not fit for a general anesthetic because of advanced cardiac or respiratory disease or where there are serious problems such as hemophilia $(9,10)$ or when a cyst involves the apices of many adjacent erupting teeth and when enucleation could affect the support and vitality of these teeth $(11,12)$.

There is an agreement that the bone graft is by far the best substitute for missing bone and the best material used as inlay grafts to improve the contour of bone, to increase the height of the alveolar process so as to improve the foundation for a denture and to fill bony cavities left after the enucleation of cysts or benign neoplasms, thus acceleration healing and maintaining the normal contour of bone (13).

The ideal graft system should satisfy the following requirements: Provides immediate osteogenesis for rapid consolidation, elects no adverse host responses such as immune reactions, facilitates revascularization which assist early healing and resistance to infection, provides a framework for osteoconduction, and be completely replaced by host bone of the same or superior quantity and quality as quickly as possible $(14,15)$.

Also the bone graft material should be biocompatible, completely biodegradable, osteoconductive, inexpensive, easy to handle, and able to support the defect area until bone growth is complete (16).

Collagenated heterologous cortico-cancellous bone mix (Osteobiol ${ }^{\circledR}$ Gel $40 \mathrm{E}$, Italy), is a medical grade xenograft which facilitates the formation of primary blood clot. Collagenated heterologous cortico-cancellous bone mix (Osteobiol ${ }^{\circledR}$ Gel 40 E, Italy) exclusive manufacturing process is able to neutralize the antigenic components present in heterologous bone (achievement of 
biocompatibility) and to preserve the collagen matrix inside the granules of biomaterial $(17,18)$.

These characteristics of collagenated heterologous corticocancellous bone mix (Osteobiol® Gel 40 E, Italy) product allow a consistent bone neoformation and a close contact between mature neo-formed bone and biomaterial granules (19).

Collagen has a key role in bone regeneration process in that it acts as a valid substrate for platelet activation and aggregation, serves to attract and differentiate the mesenchymal stem cells present in the bone marrow (17), increases the proliferation rate of the osteoblasts up to $2 / 3$ times (18) and stimulates the activation of the platelets, osteoblasts and osteoclasts in the tissue healing process (19).

Thanks to this innovative technology, collagenated heterologous cortico-cancellous bone mix (Osteobiol® Gel 40 E, Italy) has the following important characteristics: absence of a foreign body response, gradual resorption over time, stimulation and acceleration of physiological tissue healing process, capability of carrying medication to the surgical site $(20,21)$

The aim of this study is to evaluate the influence of collagenated heterologous cortico-cancellous bone mix (Osteobiol® Gel 40 E, Italy) radiologically and clinically after enculeation of mandibular cysts.

\section{MATERIALS AND METHODS}

\section{Informed consent:}

Appropriate institutional ethical clearance from the Faculty Ethical Committee and written informed consent from the patients were obtained. All patients were informed about the aim of the study.

\section{Patient selection and evaluation:}

This study was conducted on 24 patients suffering from cysts affecting the lower jaw bones and seeking for surgical treatment. Patients were assigned to 2 parallel groups with allocation ratio $1: 1$.

Patients were selected from the Outpatient Clinic of Oral and Maxillofacial Surgery Department, Faculty of Dentistry, Alexandria University.

Bone graft material was placed in group A, while group B was left to heal normally.

The Inclusion criteria of this study were patients between 20-50 years old of both sexes with good oral hygiene having intrabony cystic lesions up to $2-3 \mathrm{~cm}$ in diameter that needed enucleation. While the exclusion criteria were patients with systemic diseases affecting bone healing or patients taking radiotherapy, cysts encroaching upon important anatomical structures and soft tissues, infected cysts and keratocysts.

\section{MATERIAL}

Collagenated heterologous cortico-cancellous bone mix (Osteobiol@ Gel 40 E, Italy)

Collagenated heterologous cortico-cancellous bone mix (Osteobiol® Gel 40 E, Italy) (Figure: 1), is a medical grade xenograft facilitates the formation of primary blood clot. It is supplied in form of gel at room temperature used by simple handling technique. It enhances invasion of repairing and regenerative cells thus facilitates the physiologic tissue repair.

Tissue collagen of the material is reserved plus an additional $40 \%$ collagen gel, its physical form is collagen gel type I and III loaded with $60 \%$ bone mix, it is composed of $60 \%$ granulated mix and $40 \%$ collagen gel, its granulometry is up to $300 \mu \mathrm{m}$, re-entry time about 4 months and it is Packed as syringes of $0.5 \mathrm{cc}, 3 \times 0.5 \mathrm{cc}$.

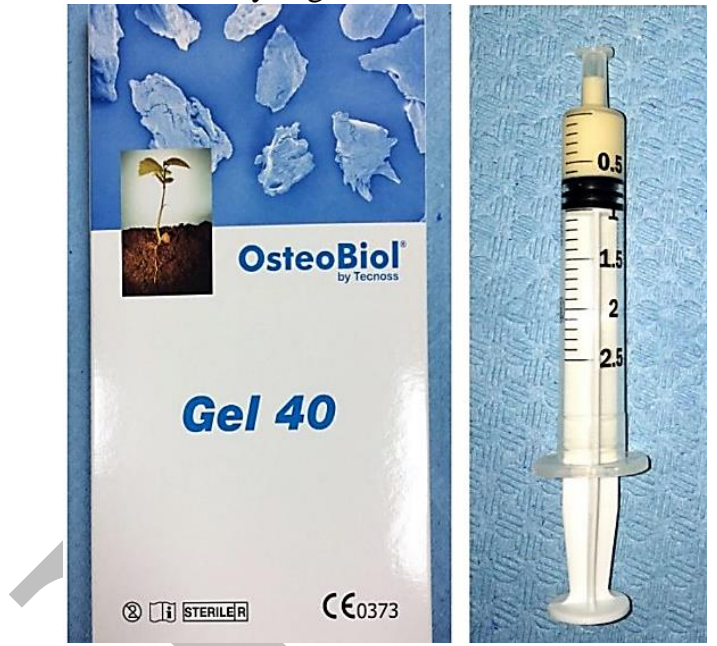

Figure (1): Collagenated heterologous cortico-cancellous bone graft material (Gel 40).

\section{Pre-operative phase:}

Presurgical clinical examination was performed for all patients: Patients data were collected; name, gender and age, medical and dental history were taken. Inspection for determining anatomical site of the lesion or defect, surface color and texture, facial asymmetry, palpation for determining consistency, tenderness, fluctuation, definition of boundaries, pulsation, mobility of teeth, and lymph nodes examination. preoperative evaluation for all patients also included panoramic $\mathrm{x}$-ray to assess the size, site, shape, extention and relation to important and vital structure of the bony defects.

\section{Surgical procedure:}

The surgical procedure was performed under aseptic conditions, and the surgical field was swabbed with $10 \%$ polyvidone-iodine solution (BETADINE, Mundipharma pharmaceutical Company, China) before the operation, then local anesthesia was given by nerve block for inferior alveolar nerve and lingual nerve of the lower jaw Mepivacaine HCL 2\% (mepecaine-L, Alexandria Co. for pharmaceuticals, Egypt). A full thickness flap was then made by using Bard-Parker blade no. 15. The flap was reflected using a periosteal elevator to expose the dental cyst as seen in (Figure: 2A) and the whole pathological tissues were enucleated. The cavity was then curetted to remove the remaining infected tissues and irrigated with normal saline as seen in (Figure: 2B). Finally, Gel $40 \mathrm{E}$ was injected inside the cavity as seen in (Figure: 3 ) and flap was repositioned and sutured by 3-0 black silk sutures.

Postoperative instructions were given to the patients including cold packs on the first day, then warm mouth wash for the following 7 days and oral hygiene instructions.

Postoperative medications including anti-biotic Amoxicillin 500mg (E-MOX, EIPICO, Egypt) cap 3 times daily for 5 days, and non-steroidal anti-inflammatory drugs Ibuprofen 400mg (IBUPROFEN, EIPICO, Egypt) 3 times daily for 3 days, and Sutures were removed one week post surgically.

\section{Post-operative evaluation:}

Follow-up was performed from the second day to the seventh day post-operatively. Healing was evaluated clinically at $2^{\text {nd }}, 4^{\text {th }}$ and $7^{\text {th }}$ day post-operatively. It was 
evaluated regarding the presence of any bleeding, pus, signs of inflammation or any dehiscence in the wound margins.

Delayed post-operative follow up was performed after six months for clinical evaluation.
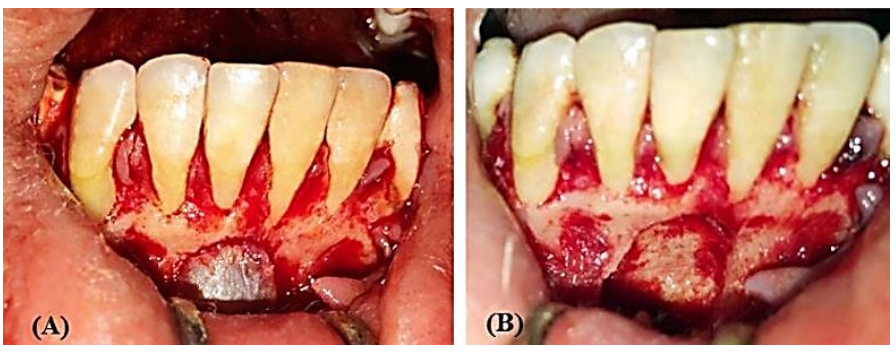

Figure (2): (A): Intrabony cystic lesion. (B) curetted bone defect after cyst enucleation

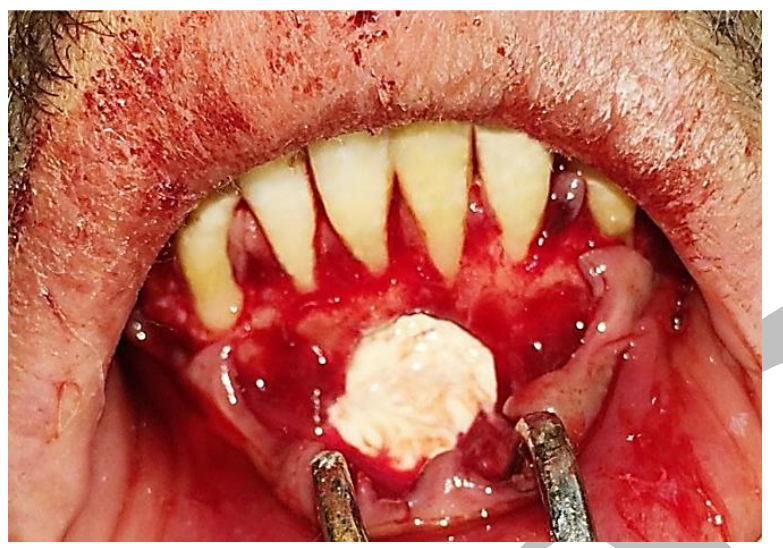

Figure (3): The cavity completely filled with bone graft material.

\section{Radiographic evaluation}

It was performed to measure the density of the new formed bone. Computerized tomography scan (CT) was taken immediately after operation and six months postoperatively for the assessment of the amount of new bone formation as seen in (Figure: 4).
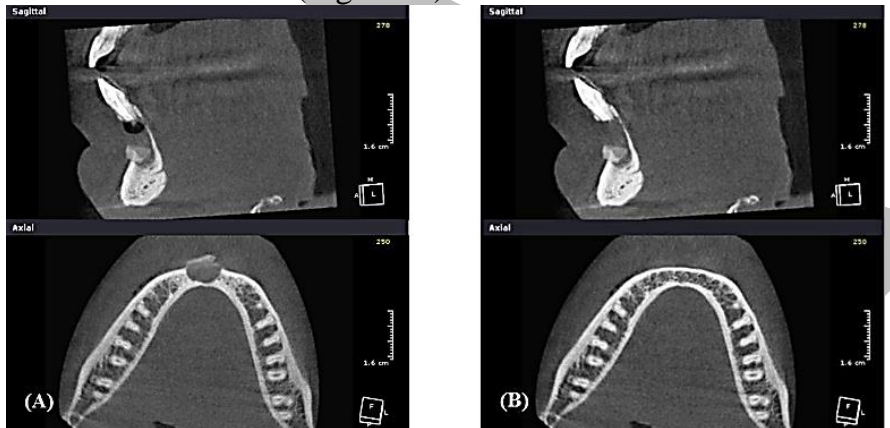

Figure (4): (A) Immediate post-operative computed tomography. (B) six months follow up computed tomography

\section{Statistical analysis of the data (22)}

Data were fed to the computer and analyzed using IBM SPSS software package version 20.0. (Armonk, NY: IBM Corp) (23) The Kolmogorov-Smirnov test was used to verify the normality of distribution Quantitative data were described using range (minimum and maximum), mean, standard deviation and median. Significance of the obtained results was judged at the $5 \%$ level.

The used tests were:

1. Student t-test: For normally quantitative variables, to compare between two studied groups.

2. Paired t-test: For normally quantitative variables, to compare between two periods.

\section{RESULTS}

This study was conducted on twenty-four patients selected from those referred to the Oral and Maxillofacial department, Faculty of Dentistry, Alexandria University. Their age ranged from 20 to 50 years.

In our series of patients, seven cases in anterior mandible and five cases in posterior mandible. The patients were nine males and three females having bony defects related to dental cause. The cysts dimension ranged from $0.9 * 1.5 \mathrm{~cm}$ to $2 * 2 \mathrm{~cm}$. All cases were augmented the defected area by collagenated heterologous cortico-cancellous bone mix (Osteobiol@ Gel 40 E, Italy).

Post-operative evaluation was performed clinically and radiographically immediately and after six months' interval. Postoperative evaluation

\section{A. Clinical results}

In all cases the clinical healing patterns were similar. The clinical findings during follow up period showed complete healing without post-operative complications after bone grafting procedures and no evidence of serious adverse local reaction (i.e., foreign bony reaction, pain, inflammation, dehiscence, or fistulas tract formation at the grafted area in all cases) was observed in any patient throughout the study. Post-operative pain:

It was measured using visual analogue pain scale (VAS). It revealed that pain decreased by days and this decrease became significant at the $7^{\text {th }}$ day post-operatively as seen in (Table: 1).

Table 1: Showing descriptive of pain score (VAS) during the different study phases.

\begin{tabular}{|l|c|c|c|c|}
\hline score (VAS) & Minimum & Maximum & Mean & SD \\
\hline score 2 2 $^{\text {day }}$ & 7.00 & 9.00 & 8.00 & 0.82 \\
\hline score 4 $^{\text {th }}$ day & 5.00 & 8.00 & 6.30 & 1.16 \\
\hline score 7 & th \\
\hline F (P) & 2.00 & 4.00 & 2.80 & 0.79 \\
\hline ll eta squared & \multicolumn{4}{|c|}{$69.2(0.000)^{*}$} \\
\hline
\end{tabular}

F: repeated measures ANOVA test

$* \mathrm{P}<0.05$ (Significant)

\section{Post-operative edema:}

Edema was evaluated post-operatively at the $2^{\text {nd }}, 4^{\text {th }}$ and $7^{\text {th }}$ days through the visual analogue scale (VAS). It was limited only to the area of operation and resolved by the $7^{\text {th }}$ day post-operatively as seen in (Table: 2 ).

Table 2: Showing descriptive of edema score (VAS) during the different study phases.

\begin{tabular}{|c|c|c|c|c|}
\hline Edema score & Minimum & Maximum & Mean & SD \\
\hline Edema score $2^{\text {nd }}$ day & 3.00 & 4.00 & 3.50 & .53 \\
\hline Edema score $4^{\text {th }}$ day & 1.00 & 3.00 & 2.00 & .67 \\
\hline Edema score $7^{\text {th }}$ day & 0.00 & 1.00 & 0.50 & .53 \\
\hline $\mathbf{F}(\mathbf{P})$ & \multicolumn{4}{|c|}{$41.7(0.000)^{*}$} \\
\hline Partial eta squared & \multicolumn{4}{|c|}{0.951} \\
\hline
\end{tabular}

F: repeated measures ANOVA test

$* \mathrm{P}<0.05$ (Significant)

\section{Dehiscence of incision line:}

All patients did not express any dehiscence of the incision line during removal of the sutures at the $7^{\text {th }}$ day postoperatively.

Inflammation of the overlying mucosa:

The mucosa covering the graft appeared to be firm and healthy without ulcers or apparent inflammation. 


\section{Post-operative complications:}

No post-operative complications were recorded regarding infection in the early follow up period.

\section{B. Radiographic results}

Radiographic analysis using cone beam computerized tomography revealed that there was gradual increase in bone densities in the grafted defects. The mean value of bone density pre-operatively in the study group was $734.8 \pm$ 105.1 HU which increased to $1634.4 \pm 222.2 \mathrm{HU}$ at the end of the follow up period.

While in the control group the mean value of bone density pre-operatively was $710.8 \pm 105.2 \mathrm{HU}$ which increased to $1298.3 \pm 189.5 \mathrm{HU}$ at the end of the follow up period as seen in (Table: 3 ) and (Figure 5).

The increase in mean value of bone density over time intervals between the study group and the control group was statistically significant with $\mathrm{p} \leq 0.05$.

Table 3: Showing comparison between the two studied cases according to bone density.

\begin{tabular}{|c|c|c|c|c|}
\hline $\begin{array}{c}\text { Bone } \\
\text { Density }\end{array}$ & $\begin{array}{c}\begin{array}{c}\text { Control } \\
(n=12)\end{array} \\
\end{array}$ & $\begin{array}{c}\text { Cases } \\
(n=12)\end{array}$ & $\mathbf{T}$ & $\mathbf{p}_{1}$ \\
\hline \multicolumn{5}{|l|}{ Immediately } \\
\hline Min. - Max. & $\begin{array}{c}580.0- \\
867.0 \\
\end{array}$ & $\begin{array}{c}590.0- \\
895.0 \\
\end{array}$ & \multirow{3}{*}{0.559} & \multirow{3}{*}{0.582} \\
\hline Mean \pm SD & $\begin{array}{c}710.8 \pm \\
105.2 \\
\end{array}$ & $\begin{array}{c}734.8 \pm \\
105.1\end{array}$ & & \\
\hline Median & 730.0 & 755.5 & & \\
\hline \multicolumn{5}{|l|}{$\begin{array}{l}\text { After 6 } \\
\text { months }\end{array}$} \\
\hline Min. - Max. & $\begin{array}{c}1064.0- \\
1553.0\end{array}$ & $\begin{array}{c}1374.0- \\
1901.0\end{array}$ & \multirow{3}{*}{$3.987^{*}$} & \multirow{3}{*}{$0.001^{*}$} \\
\hline Mean \pm SD & $\begin{array}{c}1298.3 \pm \\
189.5\end{array}$ & $\begin{array}{c}1634.4 \pm \\
222.2\end{array}$ & & \\
\hline Median & 1361.0 & 1761.0 & & \\
\hline $\mathbf{p}_{2}$ & $<0.001^{*}$ & $<0.001^{*}$ & & \\
\hline
\end{tabular}

$\mathrm{t}, \mathrm{p}_{1}$ : $\mathrm{t}$ and $\mathrm{p}$ values for Student $\mathrm{t}$-test for comparing between the two groups

$\mathrm{p}_{2}$ : $\mathrm{p}$ value for Paired t-test for comparing between immediately and after 6 months in each group

*: Statistically significant at $\mathrm{p} \leq 0.05$

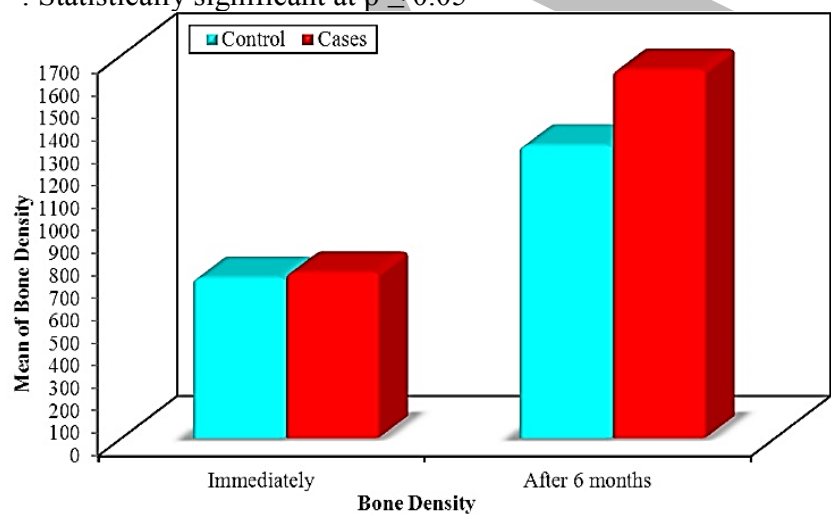

Figure (5): Comparison between the two studied cases according to bone density.

\section{DISCUSSION}

This study evaluated the use of collagenated heterologous cortico-cancellous bone mix (Osteobiol® Gel 40 E, Italy) as an osteoconductive bone graft in bony defects after mandibular cyst enucleation aiming to evaluate the bone repair.

At present the most commonly used method to achieve this is using bone substitutes. Among the bone substitute materials, xenografts are widely used because they have an adequate structure relative to the component being replaced and do not compromise the patient's remaining tissues $(24,25)$. It is previously reported that their physical and chemical properties are similar to those of human bone, so they provide an osteoconductive function (26).

Among xenogenic bone substitutes, bovine- derived bone replacement material has been extensively studied and is commonly used in clinical circumstances $(27,28)$. Regarding bovine-derived bone substitutes, however, safety concerns still remain especially with the discovery of bovine spongiform encephalopathy (29). Considering the safety of xenogenic material, an equine derived bone is proposed to be an alternative xenogenic bone substitute material.

So the present study attempted to evaluate the effect of collagenated heterologous cortico-cancellous bone mix (Osteobiol ${ }^{\circledR}$ Gel 40 E, Italy) in bone regeneration at the bone cavity consequent to mandibular cyst removal.

Cawood and Howell (30) pointed out that after a cystectomy, a progressive atrophy of the atrial lamina is observed, leading to narrowing of the dental process in the place of the previous surgical procedure.

The present clinical and radiographical data demonstrated that the equine bone substitute $\left(\mathrm{Gel} 40^{\circledR}\right)$ is biocompatible and allow regeneration of bone defects, these data are in agreement with the clinical and histological outcomes of Di Stefano et al. study (31) as the authors found that the equine enzyme deantigenated bone substitutes are biocompatible and allowed an effective reconstruction of a bone gap formed following a cyst removal.

These data are in agreement with the results of Artese et al. (32) where significantly higher microvessel density (MVD) values were found in regenerated sites when compared to control sites. These findings suggested the capacity of equine bone to support new vessel formation, which is in turn an essential condition to achieve new bone formation.

The results of Di Stefano et al. (31) study demonstrated that, even though the collagenic equine bone substitute shows a remodeling time longer than the autologous (gold standard), it can nevertheless carry on those regenerative processes essential for de novo bone formation and bone remodeling; this is evident to such an extent as to guarantee sufficient bone regeneration to allow for implant positioning within a reasonable timeframe.

Therefore, collagenated heterologous cortico-cancellous bone mix (Osteobiol® Gel $40 \mathrm{E}$, Italy) product line provide the natural substrate for correct bone tissue regeneration and repair, facilitating and accelerating the physiological regeneration process and allowing optimal results within a reasonable period of time $(33,34)$.

Finally, the clinical and radiographic evaluation of this study clearly demonstrated that the use of collagenated heterologous cortico-cancellous bone mix (Osteobiol® Gel $40 \mathrm{E}$, Italy) proved to be a suitable osteoconductive bone grafting material that can successfully enhance bone generation in bony defects.

\section{CONCLUSIONS}

From this study the following points could be concluded:

1) Collagenated heterologous cortico-cancellous bone mix (Osteobiol ${ }^{\circledR}$ Gel $40 \mathrm{E}$, Italy) is easy in its manipulation, thus it is easily packed in the defect areas. 
2) No adverse reactions that could be related to the use of this xenograft material were reported.

3) On the basis of the clinical and radiographic results of this study, it could be concluded that the use of collagenated heterologous cortico-cancellous bone mix (Osteobiol ${ }^{\circledR}$ Gel 40 E, Italy) greatly enhance bone deposition in bony defects.

\section{CONFLICT OF INTEREST}

The authors declare that they have no conflicts of interest.

\section{REFERENCES}

1. Klinge N, Hultin M. Berglundh T. Periimplantitis. Dent Clin N Am. 2005;661-76.

2. Avila-Ortiz G, Elangovan S, Kramer KWO, Blanchette D, Dawson DV. Effect of Alveolar Ridge Preservation after Tooth Extraction a Systematic Review and Meta-analysis. J Dent Res. 2014;950-8.

3. Regezi JA, Sciubba J. Clinical pathology correlation. $2^{\text {nd }} e d$. Pennsylvania: W.B. Saunders; 1993. p108-15.

4. Manor E, Kachko L, Puterman MB, Szabo G, Bodner L. Cystic Lesions of the Jaws - A Clinicopathological Study of 322 Cases and Review of the Literature. Int J Med Sci. 2012;20-6.

5. Kadam NS, De Ataide IDN, Raghava P, Fernandes F, Hede R. Management of Large Radicular Cyst by Conservative Surgical Approach: A Case Report. J Clin Diagn Res. 2014; 239-41.

6. Kethineni B, Peddi R, Puppala R, Banavath S, Chowdary UK, Raj D. Right Attitude, Right Decision and Timely Planning in Surgical Pedodontics - Scoop Out or Expose It. J Int Oral Health. 2013;44-8.

7. Soames J V, South am J C. Hyperplastic, neoplastic, and related disorders of oral mucosa. Oral Pathology. $4^{\text {th }}$ ed, Oxford University Press: New Delhi; 2005.p101-15.

8. Soliman M M, Hassan H A, Elgazaerly H, Sweedan T O. Marsupialization as a Treatment Modality of Large Jaw Cysts. WASJ. 2013;1752-9.

9. Nishijima K, Morita T, Kanehira $Y$, Higuchi $M$. Marsupialization of mandibular cystic lesions, clinical observations of 23 cases: Acta Med Okayama. 1970;373-85.

10. Howe G L. Minor Oral Surgery $3^{\text {rd }}$ ed. London: Butterworth and Co; 1985. P 29-33

11. Regezi JA, Scubba JJ, Jordan RCK. Oral Pathology Clinical Pathologic Correlations. $4^{\text {th }}$ ed. Saunders. St: Louis Missouri; 2003. p 241-4.

12. Nishide N, Hitomi G, Miyoshi N. Irrigation therapy of a dentigerous cyst in a geriatric patient: a case report. Spec Care Dentist. 2003;70-2.

13. Parel SM, Drane JB, Williams EO. Mandibular replacements: A review of literature. JADA.1977;120-9.

14. Tolman DE. Reconstructive procedures with endosseous implants in grafted bone: a revire of the literature. Int J Oral Maxillofacial Implants.1995;275-94.

15. Raghoebar GM, Batenburg RHK, Vissink A, Reintsema H. Augmentation of localized defects of the anterior maxillary ridge with autogenous bone before insertion of implants. J Oral Maxillofacial Surg.1996;1180-6.

16. Parikh S. Bone graft substitutes: past, present, future. J Postgrad Med.2002;142-8.

17. Griffith LG, Naughton G. Tissue engineering--current challenges and expanding opportunities. Science.2002;100914.
18. Reddi AH. Morphogenesis and tissue engineering of bone and cartilage: inductive signals, stem cells, and biomimetic biomaterials. Tissue Eng. 2000;351-9.

19. Nakashima N, Reddi AH. The application of bone morphogenetic proteins to dental tissue engineering. Nat Biotechnol.2003;1025-32

20. Covani U, Cornelini R, Barone A. Buccal bone augmentation around immediate implants with and without flap elevation: a modified approach the international journal of oral and maxillofacial implants. 2008;841-6.

21. Barone A, Cornelini R, Ciaglia R, Covani U. Implant placement in fresh extraction sockets and simultaneous osteotome sinus floor elevation: a case series international Int J Oral Maxillofac Implants. 2008;841-6

22. Kotz S, Balakrishnan N, Read CB, Vidakovic B. Encyclopedia of statistical sciences. 2nd ed. Hoboken, N.J.: Wiley-Interscience; 2006.

23. Kirkpatrick LA, Feeney BC. A simple guide to IBM SPSS statistics for version 20.0. Student ed. Belmont, Calif.: Wadsworth, Cengage Learning; 2013.

24. Milthrope BK. Xenografts for tendon and ligament repair. Biomaterials.1994;745-52.

25. Sogal A, Tofe AJ. Risk assessment of bovine spongiform encephalopathy transmission through bone graft material derived from bovine bone used for dental applications. J Periodontol.1990;1053-63.

26. Traini T, Valentini P, Iezzi G, Piattelli A. A histologic and histomorphometric evaluation of anorganic bovine bone retrieved 9 years after a sinus augmentation procedure. J Periodontol 2007;955-61.

27. Artzi Z, Tal H, Dayan D. Porous bovine bone mineral in healing of human extraction sockets. Part 2: Histochemical observations at 9 months. J Periodontol 2001;152-9.

28. Maiorana C, Sigurta D, Mirandola A, Garlini G, Santoro F. Sinus elevation with alloplats or xenogenic materials and implants: an up-to-4 year clinical and radiographic followup. Int J Oral Maxillofac Implants.2006;426-32.

29. Wenz B, Oesch B, Horst M. Analysis of the risk of transmitting bovine spongiform encephalopathy through bone grafts derived from bovine bone. Biomaterials.2001; 1599-606.

30. Cawood JI, Howell RA. A classification of the edentulous jaws. Int J Oral Maxillofac Surg.1988;232-6.

31. Di Stefano DA, Andreasi Bassi M, Cinci L, Pieri L, Ammirabile G. Treatment of a bone defect consequent to the removal of a periapical cyst with equine bone and equine membranes: clinical and histological outcome. Minerva Stomatol.2012;477-90.

32. Artese L, Di Stefano DA, Iezzi G, Piccirilli M, Pagnutti S, Gregorio $\mathrm{G}$, et al. Treatment of mandibular atrophy by an equine bone substitute: an immunohistochemical study. Italian Oral Surgery 2012;81-9.

33. Cardaropoli D, Cardaropoli G. Healing of gingival recessions using a collagen membrane with a demineralized xenograft: a randomized controlled clinical trial. Int $\mathbf{J}$ Periodontics Restorative Dent. 2009;59-67.

34. Nannmark U, Azarmehr I. Short communication: collagenated cortico-cancellous porcine bone grafts. A study in rabbit maxillary defects. Clin Implant Dent Relat Res. 2010;161-3. 